\title{
Environment determinants in business adoption of Cloud Computing
}

\begin{abstract}
Purpose: This paper analyzes the influence of Technology Providers, Public Administrations and R\&D Institutions on Cloud Computing adoption. This research also considers Killer Applications and Success Cases as other environmental factors.

Design/Methodology/Approach: Factorial analyses and structural equation models were used on a sample of HighTechnology firms located in technological parks in Southern Europe, with more than 10 employees and sustained investments in $R \& D$.

Findings: Results show that Technology Providers and Success Cases are determinant in Cloud Computing adoption. Moreover, Killer Applications are a forerunner for Success Cases.

Originality/value: This study contributes to Cloud Computing adoption literature because it includes Technology Providers, Public Administrations and R\&D Institutions simultaneously as well as other variables as Killer Applications and Success Cases. The importance of the external agents on IT adoption, especially when the technologies to be adopted are new and in an emergent stage, together with the lack of prior investigations focusing on specific environmental factors affecting the adoption of these new, emerging IT, justify the value of this research.

Practical implications: An appropriate fit between the tools and resources provided by suppliers and the internal resources of the company is needed to create competitive advantages. Firms should evaluate Technology Providers, identify Success Cases to Cloud Computing adoption and implement technological benchmarking.
\end{abstract}

Keywords: Adoption models, Cloud Computing, Environment, Technology Providers, Success Cases.

Paper type: Research paper. 


\section{Environment determinants in business adoption of Cloud Computing}

\section{Introduction}

In turbulent environments Information Technology (IT) combined with tangible and/or intangible resources, can be a powerful tool to attain competitive advantage (Powell and Dent-Micallef, 1997). A technological trend, named Cloud Computing, emerged to modify the use of information technology in a competitive way. In Cloud Computing (Buyya et al., 2009; Buyya et al., 2011), resources are located in virtualized and distributed environments geographically disperse. They can be accessed on an ondemand basis through web-based technologies, combining Internet connectivity and pay per use systems (Winans and Brown, 2009) in a new business model for IT provisioning (Son, et al., 2014).

The National Institute of Standards and Technology, US department of commerce defines Cloud Computing as (Mell and Grance, 2011): a model for enabling ubiquitous, convenient, on-demand network access to a shared pool of configurable computing resources (e.g., networks, servers, storage, applications, and services) that can be rapidly provisioned and released with minimal management effort or service provider interaction.

Public Administrations, R\&D Institutions and Technology Providers can arise as important environment factors in Cloud Computing adoption (Arinze and Anandarajan, 2010; Marston et al., 2011; Kenji et al., 2011), specially in the initial stages of their lifecycle (Dos Santos and Pfeffers, 1998). Other environmental factors that are acquiring particular relevance on IT adoption are Killer Applications and external Success Cases. The former allows firms to visualize the great potential of a given technology. Success Cases can stimulate IT adoption because the firms can observe and understand the real benefits of its adoption (Xu and Gutiérrez, 2006).

Knowing the role of key environmental players on Cloud Computing adoption is a relevant issue. Throughout the company evolution of the IT towards the "cloud", firms should be able to manage their organization to adapt to a future dominated by the standardization of IT infrastructures and services (Buyya et al., 2009). Within this transition, companies will act depending on the role exerted by external agents such as technology providers, $R \& D$ institutions and public administrations. The future behavior 
of each of these agents will also be affected by their role on adoption itself (Leydesdorff and Etzkowitz, 1996). However, in spite of the relevance of this question for the business management of IT, we have not identified prior research with a focus on IT adoption using these three environmental forces simultaneously.

The aforementioned reasons (importance of external agents on IT adoption, when technologies are in emergent stage and the lack of prior investigations focusing on specific environmental factors) justify the value of this research. Thus, in this study the research problem will be focused on the role of environmental agents: Public Administrations, Technology Providers and R\&D Institutions in Cloud Computing adoption. This study also seeks to analyze the effect of other variables of the environment that might prove to be relevant to explain Cloud Computing adoption such as the existence and awareness of Killer Applications and Success Cases (Low et al., 2011; Lin and Chen, 2012; Cegielski et al,. 2012). Interestingly, these latter variables have received very little attention on literature dealing with IT and particularly with Cloud Computing adoption (Alshamalia et al., 2013).

The rest of the paper is organized as follows: first, the theoretical background about IT adoption is presented. Next, research design, theoretical model and hypotheses are described, followed by the method and data analysis. Subsequently the results, their discussion and implications are presented. The research ends with main conclusions, limitations and suggestions for future research.

\section{Theoretical Background}

\section{IT adoption models in firms}

Difussion of Innovation Theory (Rogers and Shoemaker, 1971; Rogers, 1962) -a pioneering work about IT adoption-, explained innovation adoption at the individual level in terms of the characteristics of the innovation. Various models have been used to study IT adoption in the field of the organization. An approach focusing on innovation diffusion at the organizational level (Hovav et al. 2004; Dos Santos and Peffers, 1998; Rogers, 1995) considers, in addition, the external influence arising in the environment. Likewise, Contingent Models (Premkumar et al., 1997; Tornatzky and Fleischer, 1990) explain adoption by referring to three groups of factors: (1) environmental; (2) organizational; and (3) innovation characteristics. There are also partial contingent models that focuses only on a group of factors. 
Additional models have been used which stressed the modular nature of adoption, which might be split in different levels. Thus, Nambisan and Wang (1999) propose different adoption levels for Web technologies: (1) Information access; (2) collaborative work and (3) business transaction kernell. Teo and Pian (2003, 2004) provide five adoption levels of Web technologies: (1) level 0: e-mail; (2) level 1: Internet presence; (3) level 2: Prospecting; (4) level 3: Business integration and (5) level 4: Business transformation. In this paper we will use a modular model based on adoption levels to measure the evolution and use of Cloud Computing in the company.

\section{IT adoption and environmental factors}

Two mechanisms influence the adoption of a technology within a community (Dos Santos and Peffers, 1998): (1) external agents: e.g. public administrations, technology suppliers or research institutions; and (2) internal influence: when there is a sufficient critical mass (Liao et al., 1999) of adopters, the positive network externalities (Hovav et al., 2004) favor mechanisms of communication, learning and imitation between the members of the community, evident for example in the support of trading partners or customers who have already adopted the technology (Premkumar et al., 1997; Soliman and Janz, 2004) or in the positive influence of the competition (Thong, 1999).

The influence of Public Administrations, Technology Providers and R\&D institutions on IT adoption have been considered in prior research (Kuan and Chau, 2001; Quaddus and Hofmeyer, 2007; Salwani et al., 2009) but in a separated way. We have not found any prior piece of adoption research simultaneously analyzing the three environmental forces.

Other environmental factors have been considered in prior literature about IT adoption: competitors pressure; trading partners pressure and confidence in the business relationship (Premkumar et al., 1997; Soliman and Janz, 2004); business partners/clients support that already had implemented the technology and power-dependence relationship (Premkumar et al., 1997); positive network externalities (Hovav et al., 2004; Wang et al., 2005, Hsu and Fang, 2005); critical mass (Liao et al., 1999; Dos Santos and Peffers, 1998) or turbulent environments (Chau and Tam, 1997). They have been found related to IT adoption: competitors pressure, trading partners pressure, confidence in commercial relationship, commercial partners/clients support, positive network externalities and critical mass. However, Killer Applications and Success Cases, although are factors that can play a crucial role on adoption as a way to boost IT 
knowledge and use, have received little attention in research (Xu and Gutiérrez, 2006). A better, comprehensive knowledge on the factors that encourage or inhibit IT adoption would allow companies to get access to a successful adoption. Revisiting environmental adoption factors for new technologies, such as cloud computing, is therefore a relevant question that should be addressed.

\section{Cloud Computing Adoption}

Cloud Computing technologies can be classified in (Mell and Grance, 2011): (1) Private Cloud -internal cloud infrastructure in one single organization-; (2) Community Cloud -distributed infrastructure made up by a group or business partners to share business resources-; (3) Public Cloud -provisioned by the general public for open use-, and (4) Hybrid Cloud -two or more distinct cloud infrastructures (private, community, or public)-. Cloud Computing implementation can be carried out together with the next service models: (1) Software as a Service (SaaS), uses provider’s applications running on a cloud infrastructure where the applications are accessible from a thin client interface, such as a web browser (e.g., web-based email), or a program interface; (2) Platforms as a Service (PaaS), that deploys onto the cloud infrastructure consumercreated or acquired applications created using programming languages, libraries, services, and tools supported by the provider, and (3) Infrastructure as a Service (IaaS), that provides processing, storage, networks, and other fundamental computing resources where the consumer is able to deploy and run software.

Investigations on Cloud Computing adoption has diverse. Cloud computing is affected by geographical and industrial factors. Finance and business areas in educational institutions use more Cloud Computing than other industries (Tuncay, 2010). Arinze and Anandarajan (2010) examine the potential of Cloud Computing in developing countries. Low et al. (2011), use a contingent model to analyze the factors (relative advantage, complexity, compatibility, top management support, firm size, technology readiness, competitive pressure, and trading partner pressure) that affect Cloud Computing adoption by firms belonging to the high-tech industry in Taiwan. Gupta et al. (2013) highlight the easy of use, security and privacy in their study about Cloud Computing use and adoption on small and medium enterprises (SMEs). Based on diffusion of innovation theory and technology-organization-environmental framework, Oliveira et al. (2014) focus on innovation characteristics. Hsu et al. (2014) found that the perceived benefits, business concerns and IT capability are determinants of Cloud 
Computing adoption, but external pressure are not (competitors pressure, government policy, partners pressure, regulations). Finally, Lian et al. (2014) state that the most critical factors in Cloud Computing adoption are data security, perceived technical competence, cost, top manager support, and complexity.

Regarding environmental factors, some studies reported a no significant relationship between Public Administration and Cloud Computing adoption (Oliveira et al., 2014; Hsu et al., 2014). Some other authors considered R\&D institutes as an important factor for dealing with enterprises' concerns about IT standardization, security and the interoperability of cloud solutions (Low y Chen, 2012). And few studies more explore the important role of the Technology Providers in facilitating Cloud Computing adoption (Alshamalia et al., 2013; Nuseibeh, 2011).

\section{Research model and hypotheses}

\section{$R \& D$ Institutions}

Close collaboration between universities, firms and R\&D institutions can be usually related to the adoption of a particular business model or technological innovation (Leydesdorff and Etzkowitz, 1996). The link between R\&D institutions and business applications is usually supported by the creation of startups and spin-outs as a way to transfer scientific knowledge into ground-level, applied business realities. Nowadays many firms closely cooperate with universities or $R \& D$ centers and these institutions became R\&D departments of the firms. In the ground of GRID IT (the forerunner for Cloud Computing), CERN and its Large Hadron Collider (LHC) are acknowledged as one of the major landmarks for GRID utilization for scientific purposes. Likewise, many companies involved in the LHC Project have adopted GRID IT due to the influence of CERN. R\&D institutes are also cited as an important factor for dealing with firms' concerns about IT standardization, security and the interoperability of cloud solutions and to develop security standards, which jointly facilitates the Cloud Computing adoption (Low y Chen, 2012). Considering the above arguments:

H1: The higher the influence of $R \& D$ Institutions over an organization, the higher the level of Cloud Computing adoption.

\section{Technology Providers}


Many small, innovative software developers and large computer manufacturers are active in GRID IT (Maqueira et al., 2009) and Cloud Computing (Velten and Janata, 2011), and in its application in the business world (Abdulaziz 2012; Marston et al., 2012). This effect was already evident in the adoption of the Internet. Thus, firms like Cisco Systems raised awareness in many organizations about the strategic and competitive need to adapt Web technologies to their business strategies and value chain activities (Chatterjee et al., 2002). Private Technology Providers support could: (1) increase the number of organizations carrying out adoption through consortia; (2) provoke an artificial crisis by withdrawing support for technologies based on previous standards; (3) offer financial incentives to early adopters; and (4) develop transition technologies (Hovav et al., 2004).

Many large technology companies, led by Amazon, are building huge server farms to offer Cloud Computing with virtual applications and business software with selfservice interfaces so that customers can use resources when they want (Chris, 2011). Furthermore, an increasing number of Cloud Computing technological providers are ready to attract companies to Cloud business models (Marston et al., 2011). Thus, key Technology Providers (like Apache, EMC or Cisco) adapt their technologies to facilitate firms access to the Cloud. Established key players (as Google, IBM or Microsoft) and also innovators (as Amazom or Salesforce) exert and influence adoption through marketing action among potential customers and enablers (like CapGemini or RightScale). Furthermore, these companies closely cooperate with clients to offer products and services that use or are intimately related to Cloud computing adoption (Marston et al., 2011).

Furthermore, private support can become even more influential if the relationship between the customer firm and its technology provider is highly dependent (Hsu et al., 2014). Cloud Computing adoption will depend on the balance of bargaining power in the commercial relationship, and will be stronger when the supplier or customer with this adopted technology is key for the business of the other party that has not adopted the technology yet (Premkumar et al., 1997). The support for implementing and using cloud services made available by cloud services providers is likely to motivate enterprises to adopt Cloud Computing (Alshamalia, et al., 2013). Thus, the following hypothesis is proposed: 
H2: The higher the influence of Technology Providers the higher the level of Cloud Computing adoption.

\section{Public Administrations}

Public Administrations might have played a key role as drivers for many cloud based research and development projects (Marston et al., 2011), for example, in one of the most powerful GRID IT facilities in the world: the development of the EGEE infrastructure in Europe (Maqueira and Bruque, 2007). Recently, the governments of several countries are considering Cloud Computing potential as a way to upgrade the services offered to their citizens, specially within the tax administration service (Navonil, 2010). Some examples led by public administrations that also involved many private companies are the British G-Cloud, a part of the Digital Britain Plan; the United States’ Apps. Gov, Japan’s Kasumigaseki, the European Union’s EuroCloud, and South Korea’s governmental Cloud Computing plan (Yang and Hsu, 2011).

Public Administrations' role on technology adoption might be twofold. On the one hand, Public Administrations can be companies' clients or suppliers (Janssen and Joha, 2011). On the other hand, they can influence on companies with public subsides, technology promotion initiatives or by introducing legal changes favorable to IT adoption (Hovav et al., 2004). Public Administrations might establish, for instance, a common regulatory framework able to ensure an appropriate policy for data protection and security as well as to favor fair contractual relations between the parties (suppliers and clients of cloud services which commonly act in a globalized environment) (Marston et al., 2011). A wide emphasis on the importance of government regulations at the national and international levels and the lack of government regulations can hinder enterprises from adopting the cloud (Lian et al. 2014). These arguments lead to the following hypothesis:

H3: The higher the influence of Public Administration on a given organization the higher the level of Cloud Computing adoption.

\section{Killer Applications}

Killer Application is a service or application able to create value and that is quickly recognized and used by an increasing number of users (Xu and Gutiérrez, 2006) and that is also an enabler or promoter of the use of related technologies. Thus, the email was a Killer Application for web technologies and SMS was a Killer Application 
for the use of mobile telephones (Xu and Gutiérrez, 2006). Other examples for web technologies were the Internet search engine Google, Voice over IP such as Skype or, more recently, video screening systems through the Internet (Shin, 2006) such as YouTube or social electronic networks like Foursquare. Firms like Foursquare hold all their infrastructure hosted in the Amazon EC2 servers. Emerging cloud models the ones more appropriate to satisfy traffic and concurrency needs (Buyya et al., 2009). Therefore, a positive relationship between the existence of Killer Applications in the Internet age and Cloud Computing adoption could arise. Products like Google’s Gmail, -a Cloud killer application-, encourage many firms to use Cloud services provided by Google App.

In Cloud Computing literature, the Amazon EC2 models are considered as Killer Applications related to Cloud Computing (Abdulaziz, 2012). They might be succeeding in attracting many users through imitation or contagion (Dos Santos and Peffers, 1998; Middleton, 2007). In fact, many successful companies working in Internet-related services such as Reddit, Quora and Foursquare, use their IT services. Based on Institutional Theory (DiMaggio and Powell, 1983), Killer Applications might favor mimesis or imitative behavior, which is a powerful explicative factor of IT adoption in companies. Therefore, we propose the following hypothesis:

H4: The higher managers' awareness of Killer Applications based on Cloud Computing, the higher the level of Cloud Computing adoption.

Killer Applications might be closely related to the $R \& D$ Institutions and Technology Providers. Killer Applications may act as triggers so that these two agents would be more motivated to attain quicker and deeper access to the technical foundations and knowledge underlying Cloud Computing as well as to Cloud-related know-how. The accumulated knowledge of R\&D Institutions may materialize in a higher likelihood of tight cooperation with companies which in turn may evolve towards higher levels of Cloud adoption. These arguments lead to the following hypotheses:

H5: The higher managers' awareness of Killer Applications based on Cloud Computing, the higher the influence of $R \& D$ institutions on Cloud Computing adoption.

H6: The higher managers' awareness of Killer Applications based on Cloud Computing, the higher the influence of Technology Providers on Cloud Computing adoption. 


\section{Success Cases}

Success Cases are specific and well defined applications able to solve a business problem in an efficient way. Unlike Killer Aplications, Success Cases are not very popular, and have not many users and, therefore, have a more limited application scope. So, generally its use is restricted in a particular industry. Success Cases are intensively used by technology providers, who include them into their websites as a promotion instrument (Alshamaila and Papagiannidis, 2013). Thus, their potential clients can visualize the effects of the new technology. So, Technology Providers try to attract interest on their products/services, increasing their sales opportunities.

This can explain why adoption models have included Success Stories/Cases among the potential enablers of technology adoption (Moore, 1995). Furthermore, Success Cases in key industries can act on IT adoption in a bowling effect way: a given Success Case, through an increased, extended confidence, is able to create momentum, thus influencing many companies towards technology adoption so that adopters can cross the chasm which separates the area of early adoption, also called early market from the area of massive adoption in the first majority or principal market (Rogers, 1995; Moore, 1991, 1995). This thrust effect is usually assisted by a strong imitative effect (DiMaggio and Powell, 1983).

The European project BEINGRID (25 Cloud Computing/GRID IT success cases in different industries) tries to promote success cases in each industry, thus nurturing an imitative effect so that Cloud Computing/GRID IT could be massively adopted (Dimitrakos et al., 2010). IT cloud providers' demonstration of successful business cases and models are likely to increase Cloud Computing adoption rates (Alshamaila and Papagiannidis, 2013). Observing perceived benefits from using Cloud Computing can be an important motivation towards its adoption (Low et al., 2012; Lin and Chen, 2012, Cegielski et al. 2012). Therefore, the following hypothesis is proposed:

H7: The higher managers' awareness of Success Cases in Cloud Computing, the higher the level of adoption of Cloud Computing.

Killer Aplications and Success Cases might be related. A Killer Application can be visualized and widely recognized in multiple sectors, which may favor technology awareness by other agents working in different industries. Thus, awareness about Killer Applications might cause a sense of urgency among potential technology adopters to 
rise. Early adopters in some industries might be visualized by other potential early adopters as Success Cases. This enables to state the following hypothesis:

H8: The higher the number of Killer Applications related to Cloud Computing, the higher the number of Cloud Computing Success Cases.

Success Cases might be fostered by R\&D Institutions, Technology Providers and Public Administrations. Likewise, the higher the number of Success Cases, closely related to Cloud developers, the higher business partners are able to increase their internal technological know-how. Indirectly, through increasing the internal technological expertise, R\&D Institutions can increase their influence over potentially adopting organizations (Montealegre, 1999). The same rationale can be applied to Technology Providers that might be also seen by clients as the most appropriate collaborators in technology adoption. Success Cases may also act as technology transfer promoters for Public Administrations, aiming and fostering initiatives related to the diffusion of public programs among potential adopters (Dimitrakos et al., 2010). These arguments lead to the following hypotheses:

H9: The higher managers' awareness of Success Cases in Cloud Computing, the higher the influence of $R \& D$ Institutions on Cloud Computing adoption.

H10: The higher managers' awareness of Success Cases in Cloud Computing, the higher the influence of Technology Providers on Cloud Computing adoption.

H11: The higher managers' awareness of Success Cases in Cloud Computing, the higher the influence of Public Administrations on Cloud Computing adoption.

Figure 1 depicts the research model. 


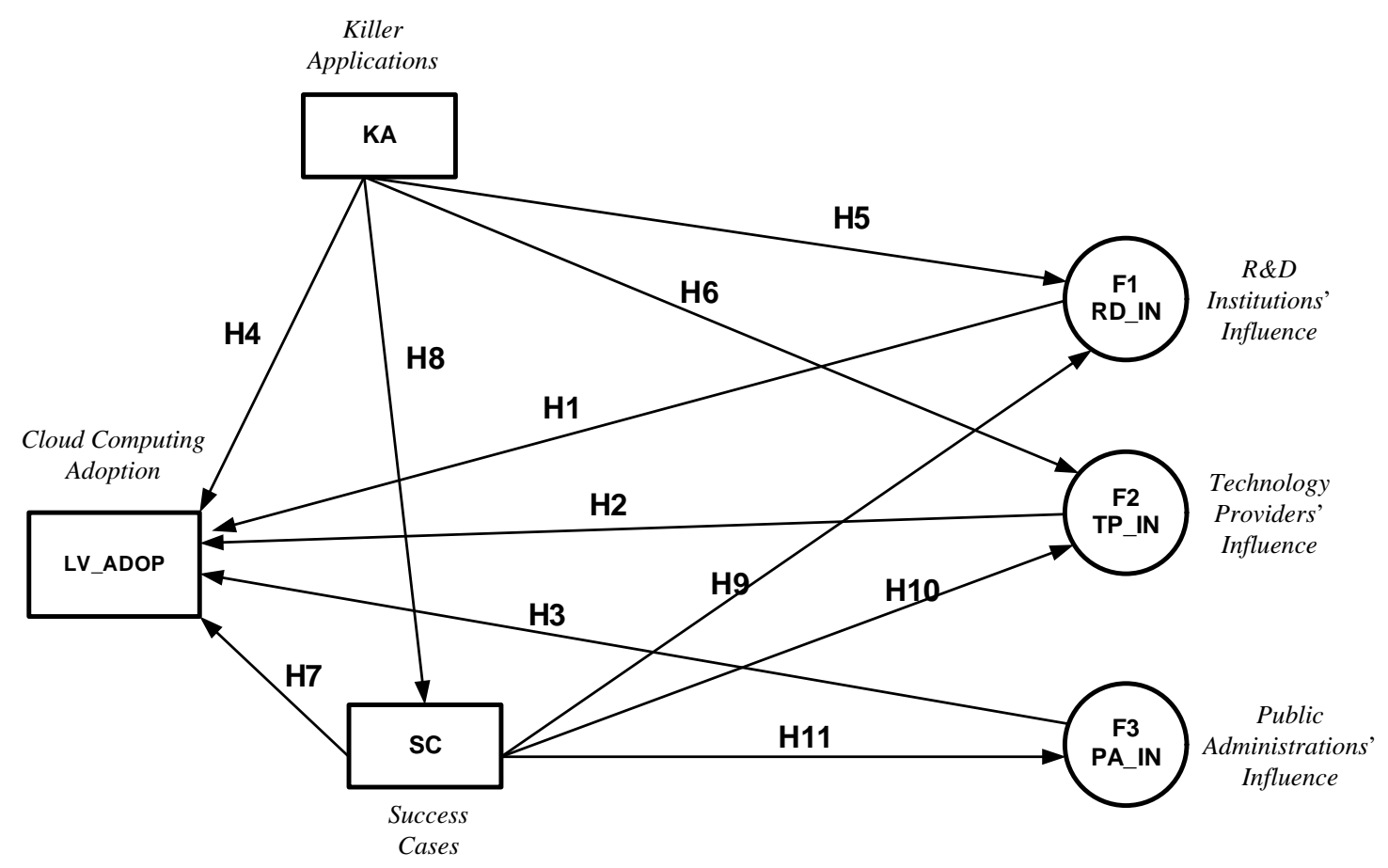

Figure 1. Research Model.

\section{Research Methodology}

\section{Sample and data collection}

In 2013, 79 technological parks in Spain hosted 5,115 companies with an accumulated turnover of 21,256 million euro. These companies employed 136,218 workers, 23,138 of them were directly related to R\&D (APTE, 2013). The population in this study comprises 1,330 high-technology firms located in technological parks in Spain with more than 10 employees and sustained investment in R\&D (APTE, 2013).

A questionnaire was used to collect data. Final data gathering was carried out through a phone interview using a Computer Aided Telephone Interviewing (CATI) which ensured data had been collected randomly and that contributes to the sample representativeness (Synodinos and Brennan, 1988).

Informants were Chief Information Officer (CIO) or Chief Executive Officer (CEO). 281 valid questionnaires were gathered (21.13\% response rate), which can be considered as an on-average or even higher response rate compared to works dealing with similar populations and research topics (Chatterjee et al., 2002). Table 1 gathers sample distribution regarding sizes and informants. Table 2 exhibits sectorial sampling distribution. 


\begin{tabular}{lrr}
\hline Table 1. & \multicolumn{2}{c}{ Sample } \\
\hline Sample Distribution & $\mathbf{n}$ & $\mathbf{\%}$ \\
\hline Size (number of employees) & & \\
& 182 & 64.77 \\
Between 11 and 100 & 43 & 15.30 \\
Between 100 and 200 & 27 & 9.61 \\
Between 200 and 500 & 29 & 10.32 \\
More than 500 & 281 & 100 \\
Total & & \\
& & \\
Informants & 52 & 18.50 \\
CEO & 229 & 81.50 \\
CIO & 281 & 100 \\
Total & & \\
&
\end{tabular}

\begin{tabular}{lrrrr}
\hline $\begin{array}{l}\text { Table 2. } \\
\text { Sectorial sample distribution }\end{array}$ & & & $\begin{array}{r}\text { Total firms in } \\
\text { Technological } \\
\text { Parks }\end{array}$ \\
\hline Sector & n & \% & n & \% \\
\hline Automotive and Aeronautics & 12 & 4.3 & 102 & 2 \\
Training and Human Resources & 13 & 4.6 & 153 & 3 \\
Information, Informatics and & 83 & 29.5 & 1381 & 27 \\
Telecommunications & 17 & 6.0 & 358 & 7 \\
Health and Medicine & 22 & 7.8 & 205 & 4 \\
Agrifood and Biotechnology & 14 & 5.0 & 153 & 3 \\
Electronics & 26 & 9.3 & 307 & 6 \\
Manufacturing & 46 & 16.4 & 716 & 14 \\
& & & & \\
Engineering \& Consulting & 12 & 4.3 & 307 & 6 \\
Energy and Environment & 36 & 12.8 & 307 & 6 \\
Technological Centres and R\&D & 0 & 0 & 1126 & 22 \\
Others & 281 & 100 & 5115 & 100 \\
Total & & & & \\
& & & & \\
\hline
\end{tabular}

\section{Measures}

R\&D Institutions influence, Public Administrations influence and Technology Providers influence have been measured using instruments proposed and validated in prior research. Killer Applications and Success Cases variables have been operationalized through direct questions (Xu and Gutiérrez, 2006). Cloud Computing 
adoption has been built up using the same methodology employed to measure Web adoption levels (Nambisan and Wang, 1999; Teo and Pian, 2003, 2004) and including the taxonomy of Cloud Computing (Mell and Grance, 2011). Therefore, our scale of Cloud Computing adoption includes four basic adoption levels: (1) MicroCloud, small internal Cloud with experimental purposes; (2) Private Cloud, internal Cloud infrastructure which covers just one single organization; (3) Community Cloud, distributed infrastructure made up by a group of business partners closely linked in order to share business resources and (4) Public Cloud, infrastructure managed and provided by professional technology providers which offer services to business clients. Furthermore, a pre-adoption stage made up by three sublevels: (0_1) utilization of clusters just for experimental purposes; (0_2) utilization of departmental clusters, and (0_3) utilization of interdepartmental clusters.

Table 3 shows measure variables. Table 4 shows the Cloud Computing adoption scale, indicating if it is a pre-adoption or adoption level.

Table 3. Scales, measure variables and sources

\begin{tabular}{|c|c|}
\hline Measures & Authors \\
\hline \multicolumn{2}{|l|}{$\begin{array}{l}\text { With regards to the institutions that carry out } R \& D \text { in your environment, } \\
\text { your opinion is that: }\end{array}$} \\
\hline $\begin{array}{l}\text { 1. (RD_IN1) They would be willing to cooperate with my organization } \\
\text { 2. (RD_IN2) They would be willing to lightly severe cooperative relations with } \\
\text { my organization } \\
\text { 3. (RD_IN3) They will not seek to take advantage of our cooperation } \\
\text { relationship }\end{array}$ & Wu (2006) \\
\hline \multicolumn{2}{|l|}{$\begin{array}{l}\text { You think that, among the Cloud Computing providers, there are some } \\
\text { companies that are willing to: }\end{array}$} \\
\hline $\begin{array}{l}\text { 1.(TP_IN1) Cooperate with my organization } \\
\text { 2.(TP_IN2) Hold a severe cooperative relations with my organization } \\
\text { 3.(TP_IN3) They will not seek to take advantage of our cooperation } \\
\text { relationship }\end{array}$ & Wu (2006) \\
\hline \multicolumn{2}{|l|}{ With regards to Public Administrations and Cloud Computing: } \\
\hline $\begin{array}{l}\text { 1. (PA_IN1) Public Administrations are leaders with regards to these } \\
\text { technologies } \\
\text { 2. (PA_IN2) Public Administrations already use Cloud Computing } \\
\text { 3. (PA_IN3) Public Administrations provide direct financial support and } \\
\text { efficient infrastructures to promote the use of Cloud Computing }\end{array}$ & $\begin{array}{l}\text { Quaddus and } \\
\text { Hofmeyer (2007); } \\
\text { Teo et al. (1997); } \\
\text { Premkumar and } \\
\text { Roberts (1999) }\end{array}$ \\
\hline
\end{tabular}

Killer Applications

1. (KA) I know one or several applications (Killer Applications) which confirm $\quad$ Xu and Gutiérrez the great potential of Cloud Computing (2006)

Success Cases

1. (SC) I know one or several Success Cases which encourage to use Cloud $\quad$ Xu and Gutiérrez Computing in my Organization (2006) 
Table 4. Cloud computing adoption scale

\begin{tabular}{|c|c|c|c|}
\hline LEVEL & DESCRIPTION & ITEM & CLOUD \\
\hline Level 0_1 & $\begin{array}{l}\text { Experimental } \\
\text { cluster }\end{array}$ & $\begin{array}{l}\text { We use a cluster made up by a limited } \\
\text { number of computers just for experimental } \\
\text { purposes. }\end{array}$ & NO \\
\hline Level 0_2 & $\begin{array}{l}\text { Departmental } \\
\text { cluster }\end{array}$ & $\begin{array}{l}\text { We use a cluster made up by a limited } \\
\text { number of computers connected through a } \\
\text { local area network in a particular } \\
\text { department for operational purposes. }\end{array}$ & NO \\
\hline Level 0_3 & $\begin{array}{l}\text { Interdepartmental } \\
\text { cluster }\end{array}$ & $\begin{array}{l}\text { We use clusters made up by computers } \\
\text { connected through a local area network, } \\
\text { connecting several departments mostly for } \\
\text { operational purposes. }\end{array}$ & NO \\
\hline Level 1 & MicroCloud & $\begin{array}{l}\text { We use clusters made up by computers } \\
\text { connected through a wide area network, } \\
\text { connecting several departments mostly for } \\
\text { operational purposes. }\end{array}$ & YES \\
\hline Level 2 & Private Cloud & $\begin{array}{l}\text { In our organization, Cloud Computing is } \\
\text { used grouping a big number of resources, } \\
\text { mostly for operational purposes within the } \\
\text { organization. }\end{array}$ & YES \\
\hline Level 3 & $\begin{array}{l}\text { Community Cloud } \\
\text { (Private Cloud } \\
\text { with partners) }\end{array}$ & $\begin{array}{l}\text { In our organization, Cloud Computing is } \\
\text { used grouping a big number of resources, } \\
\text { mostly for operational purposes, allowing } \\
\text { interaction with other organizations which } \\
\text { also provide resources and with which we } \\
\text { are connected through strong links. }\end{array}$ & YES \\
\hline Level 4 & Public Cloud & $\begin{array}{l}\text { In our organization, Cloud Computing is } \\
\text { used to gather a big number of resources } \\
\text { coming from heterogeneous external } \\
\text { organizations freely associated through a } \\
\text { wide global network. }\end{array}$ & YES \\
\hline
\end{tabular}

Content validity was ensured through a questionnaire analysis carried out by 5 academics and 2 managers directly related to Cloud Computing. Scale unidimensionality was assessed through an Exploratory Factor Analysis, providing eigenvalues higher than 1 , standardized factorial loads of observed variables higher than 0.5, a significant explained variance for each extracted factor and high values for ChiSquared/degrees of freedom in Barlett's sphericity test $(\mathrm{p}<.05)$. Therefore, one single factor was extracted in each of the proposed scales: Influence of $R \& D$ Institutions, Influence of Technology Providers and Influence of Public Administrations. Table 5 shows results for the Exploratory Factor Analysis. Based on IT adoption research (Premkumar, 2003), the Composite Reliability Index (CRI) was used to test measures’ reliability, with scores higher than 0.6 (Bagozzi and Yi, 1988). 
Table 5. Exploratory Factor Analysis

\begin{tabular}{llcccc}
\hline \multicolumn{1}{c}{ Factor } & Variable & CRI & $\begin{array}{c}\text { Standardized } \\
\text { Factor Loading }\end{array}$ & $\begin{array}{c}\text { Barlett } \\
\text { Test }\end{array}$ & $\begin{array}{c}\text { \% Explained } \\
\text { Variance }\end{array}$ \\
\hline R\&D Institutions' & RD_IN1 & & .903 & $X^{2}=283.276$ & \\
Influence & RD_IN2 & .71 & .911 & g=3 & 65.135 \\
& RD_IN3 & & .557 & sig=.00 & \\
\hline Technology & TP_IN1 & & .882 & $X^{2}=258.669$ & \\
Providers' & TP_IN2 & .75 & .894 & g=3 & 66.481 \\
Influence & TP_IN3 & & .647 & sig=.00 & \\
& PA_IN1 & & .817 & $X^{2}=108.316$ & \\
\hline Public & PA_IN2 & .65 & .754 & g=3 & 57.872 \\
Administrations' & PA_IN3 & & .708 & sig=.00 & \\
Influence & KA & & --- & --- & --- \\
\hline------- & SC & & --- & -- & -- \\
\hline------- & &
\end{tabular}

A Confirmatory Factor Analysis (CFA) was performed, using EQS 6.1, to analyze scales' dimensionality and test convergent validity. First, a data exploration was carried out through normalized estimation of Mardia's test (Bentler and Wu, 2002), which confirmed multivariate non-normality of data, so we could apply the Robust Maximum Likelihood method. Thus, a factor model was designed including the 9 observed variables, three for each construct. Once the measurement model was tested, yet all indicators were significant and the overall model presented a satisfactory goodness of fit, it was necessary to rule out all the factors whose standardized loads were lower than 0.5 or which had a $\mathrm{R}^{2}$ score lower than 0.3 (Kline, 1998). The final fit of the Confirmatory Factor Analysis was highly satisfactory (Kline, 1998) (Scaled, Satorra-Bentler's $X^{2}=6.245$; degrees of freedom $\mathrm{g}=6 ; X^{2} / g=1.04$; RMSEA=.012; $\mathrm{MFI}=1 ; \mathrm{NFI}=.985 ; \mathrm{NNFI}=.998 ; \mathrm{CFI}=.999 ; \mathrm{IFI}=.999)$. Standardized factorial loads and $\mathrm{R}^{2}$ are shown in Table 6.

Table 6. Confirmatory Factor Analysis

\begin{tabular}{|c|c|c|c|}
\hline Factor & Variable & $\begin{array}{r}\text { Standardized } \\
\text { Factor Loading }\end{array}$ & $\mathbf{R}^{2}$ \\
\hline \multirow{2}{*}{$\begin{array}{l}\text { R\&D Institutions' } \\
\text { Influence }\end{array}$} & RD_IN1 & 0.774 & 0.600 \\
\hline & RD_IN2 & 1.000 & 1.000 \\
\hline \multirow{2}{*}{$\begin{array}{l}\text { Technology Providers' } \\
\text { Influence }\end{array}$} & TP_IN1 & 1.000 & 1.000 \\
\hline & TP_IN2 & 0.731 & 0.534 \\
\hline \multirow{2}{*}{$\begin{array}{l}\text { Public Administration’ } \\
\text { Influence }\end{array}$} & PA_IN1 & 0.615 & 0.379 \\
\hline & PA_IN2 & 0.713 & 0.509 \\
\hline ------ & KA & --- & -- \\
\hline ------- & $\mathrm{CE}$ & --- & --- \\
\hline
\end{tabular}


Discriminant construct validity was confirmed as per comparison of correlation coefficients (Table 7) between constructs/variables, which in all cases are relatively low (no >.8) but not too low (>.10) (Kline, 1998). A structural equation model was developed (Figure 2). We used EQS and the Robust, Maximum Likelihood Method because it is the most appropriate for non-normal settings (Satorra, 2002).

Table 7. Descriptive statistics and correlation matrix

\begin{tabular}{lrrrrrrr}
\hline \multicolumn{1}{c}{ Factor/Variable } & Mean & $\begin{array}{r}\text { Standard } \\
\text { deviation }\end{array}$ & $\mathbf{1}$ & $\mathbf{2}$ & $\mathbf{3}$ & $\mathbf{4}$ & $\mathbf{5}$ \\
\hline 1. R\&D Institutions influence & 5.514 & 1.224 & & & & & \\
2. Technology Providers Influence & 5.324 & 1.234 & $.198^{* *}$ & & & & \\
3. Public Administrations Influence & 3.710 & 1.328 & $.135^{*}$ & .060 & & & \\
4. Killer Applications & 4.655 & 1.890 & .105 & $.285^{* *}$ & .012 & & \\
5. Success Cases & 4.885 & 1.785 & .023 & $.291^{* *}$ & .020 & $.674^{* *}$ & \\
\hline$N=281 ; * p<0.05 ; * * p<0.01$ & & & & & & & \\
\hline
\end{tabular}

\section{Results, discussion and implications}

\section{Results}

The model yielded an overall good fit (Satorra-Bentler's scaled $X^{2}=33.6067$; $\mathrm{g}=19 ; X^{2} / g=1.769, \quad \mathrm{RMSEA}=.052 ; \quad \mathrm{NFI}=.952 ; \quad \mathrm{NNFI}=.958 ; \quad \mathrm{CFI}=.978 ; \quad \mathrm{IFI}=.978 ;$ MFI=0.974) (Figure 2). Significant relationships $(\mathrm{p}<.05)$ are those included in H2, H5, H6, H7, H8 and H10 whereas that hypotheses H1, H3, H4, H9 and H11 do not receive enough support.

Results show that the environmental factors that explain Cloud Computing better adoption are Technology Providers (H2) and Success Cases (H7). Conversely, neither Public Administrations nor R\&D Institutions exert a significant effect on adoption. Furthermore, Technology Providers’ influence is mediated by the managers’ awareness of Killer Applications (H6) and Success Cases (H10) and R\&D Institutions' influence is mediated by the managers' awareness of Killer Applications (H5). Moreover, Success Cases do not modify the effect of Public Administrations (H11) whereas of Killer Applications is a direct cause for Succes Cases (H8). 


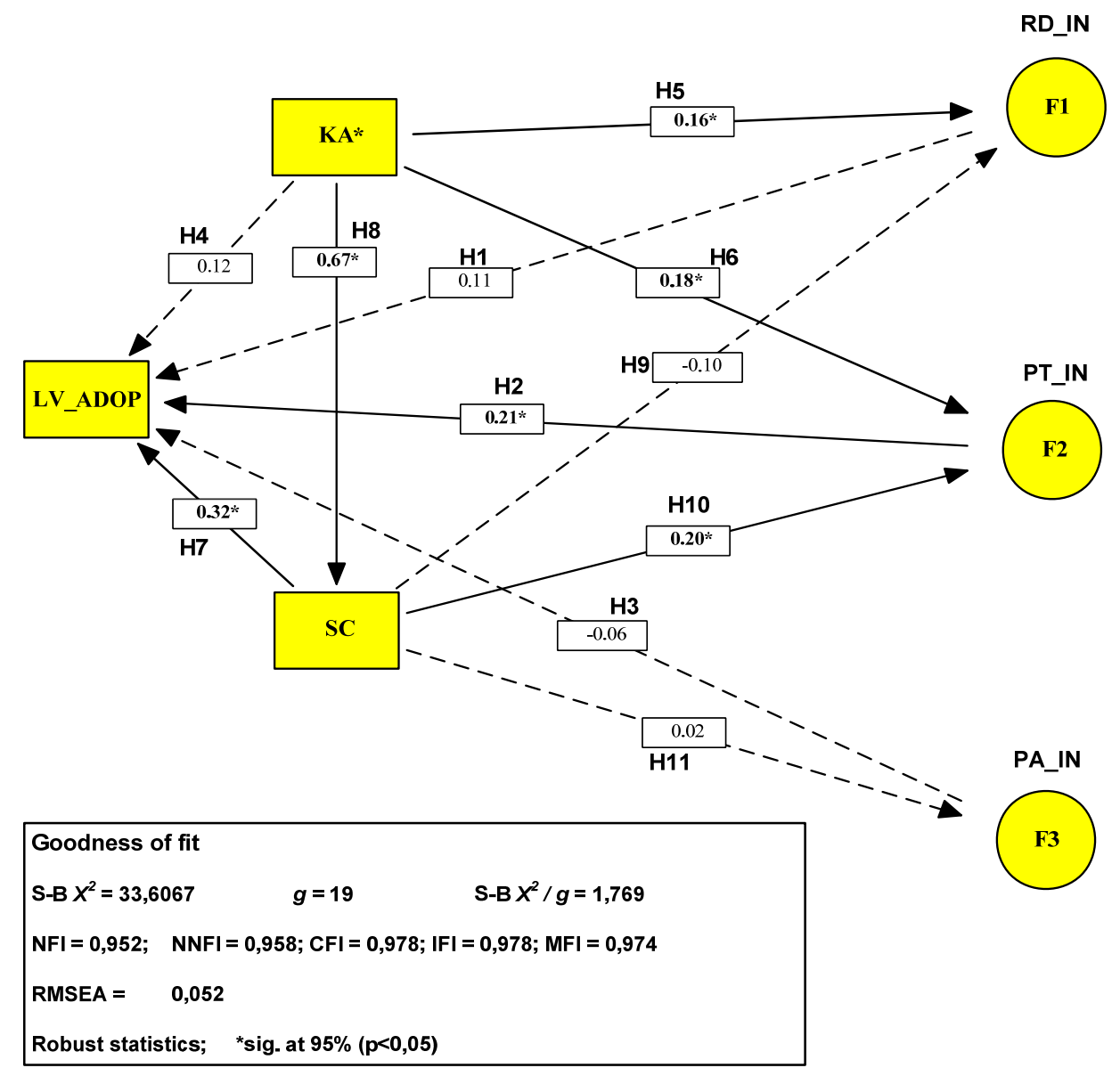

Figure 2. Structural Equations Results

\section{Discussion}

Technology Providers are a key factor of Cloud Computing adoption. This result is also supported by research on other IT with a strong organizational nature such as ecommerce between companies (B2B) (Quaddus and Hofmeyer, 2007) or innovative ITrelated services (Frambach et al., 1998).

Cloud Computing is creating a breakthrough in the market since it is shaping a new paradigm in the form of IT services that are commoditized and delivered in a similar way such as in traditional utilities like water, electricity, gas and telephony. This is the reason why Cloud Computing has been called the $5^{\text {th }}$ utility (Buyya et al., 2009). Some reports (Velten and Janata, 2011) highlight the role played by Technology Providers in the market of Cloud Computing and how companies like Google, Amazon, IBM, BT, HP, Fujitsu, Dell, T-Systems, Oracle or Vodafone are carrying out big investments and deploying huge infrastructures to compete and reach small and big companies through systems such as IaaS, PaaS and SaaS. Cloud Computing is being adopted quickly in the business arena (Arinze and Anandarajan, 2010; Low et al., 2011) 
for small, medium and large enterprises, in industries such as the Automotive, Aerospace, Financial Services, Logistics, Textile or Health (Dimitrakos et al., 2010).

With revolutionary effects on business (Marston et al., 2011), Cloud Computing is able to strengthen firm capabilities (Iyer and Henderson, 2010) and increase business value (Abdulaziz, 2012). Some Cloud Computing's benefits can be instant global platforms, elimination of hardware infrastructures and software licenses, reduced costs (Benlian and Hess, 2011), simplified scalability and the elimination or reduction of disaster recovery risks and its high costs (Tuncay, 2010).

Some reasons might explain the key role played by Technology Providers. Small companies can benefit from services provided by a cloud provider because they do not have the necessary budget and knowledge to build and maintain their own infrastructure. Large providers own scalable resources and a professionally operated infrastructure which small companies cannot afford (Repschlaeger et al., 2013). Cloud adoption by SMEs depends on how the cloud providers build trust through their cloud services, fostering sharing and collaboration via cloud tools (Gupta et al., 2013).

Medium and large firms are looking for not just technological suppliers but for actual technological partners able to provide support and valuable know-how. Thus, many firms rely on strong ties with trading partners for their IT design, implementation and operations tasks (Pan and Jang, 2008). IT providers have been able to accumulate and nurture knowledge on the factors that allows us to understand complexity related to Cloud Computing. This accumulated knowledge on the elements that disentangle Cloud complexity would be boosting adoption of hybrid clouds. Hybrid clouds have been created by IT providers to transform the company's infrastructure into private clouds that coexist and are eventually integrated within public clouds. These public clouds are also offered by a reduced number of IT providers. Likewise, clients would be able to take advantage of an appropriate fit between IT itself and the remaining bundle of complementary resources within the organization. Our results show that Technology Providers have succeeded in performing this twofold role (partner and supplier). However, Public Administration and R\&D Institutions have failed in this role in light of our results. This conclusion is also supported by literature; trading partners was just the factor with a stronger influence in Cloud Computing adoption (Low et al., 2011). Furthermore, Quaddus and Hofmeyer (2007) also found that Public Administrations are not determinant on B2B adoption while Zhang and Si (2008) found that R\&D 
Institutions have not a direct effect on technology adoption by companies (although there might be an indirect, mediating effect).

R\&D Institutions would be performing a remarkable role on the development of the technology itself but not on actual technology adoption by companies. R\&D Institutions and Public Administrations would not be that closely linked to the daily activity of firms (Bakouros et al., 2002) since they usually work under a target and timeline framework which is not the same as the one valid for companies. For instance, CERN played an important role in the development of the World Wide Web, but its influence on actual Internet adoption by companies was really limited.

Probably, Public Administrations are not still aware of the actual relevance of Cloud Computing and, although efforts are being put into place to promote adoption by companies, Public Administrations have still a long way ahead to promote adoption effectively.

It is particularly remarkable the effect exerted on adoption by the existence of Success Cases and its awareness among managers. Success cases can be a storefront where companies visualize the effects on Cloud Computing adoption. These success cases, boosted by IT providers, increase, through a positive feedback effect, the influence of IT providers on adoption. This loop will generate new and powerful success cases that will keep fostering adoption. Whilst Killer Applications do not exert a significant influence. This fact can be explained because of the difficulty in reproducing the success attained by a particular Killer Application in different environments. For instance, electronic social networks such as Facebook or Twitter (included within the so-called Web 2.0) are Killer Applications to Web Technologies. However, massive use of social networks for private purposes has not led firms to use them to internally interconnect their employees. Conversely, Success Cases are more directly connected to the daily reality of firms, allow to visualize how a given technology solve usual, concrete problems efficiently, can be better understood in the business setting and can be easily generalize. In turn, all these facts facilitate technology adoption and diffusion by other peer companies.

Furthermore, results show how Technology Providers are aware of and use Killer Applications and Success Cases indeed to promote ulterior adoption of Cloud Computing (Alshamaila and Papagiannidis, 2013). Technology Providers usually develop a continuous work of technological surveillance to not fall behind in the competition race against other players in the market. This technology surveillance 
carried out by Technology Providers is probably more intense than the one carried out by Public Administrations. Finally, Killer Applications are a forerunner for Success Cases because facilitate that a given technology (for example, Cloud Computing) can be easily applied to business problems which, under certain conditions, can build up a Success Case if the application is successful, innovative and takes place in the early stages of adoption.

\section{Implications}

Managers who wish to adopt Cloud Computing in their organizations should pay special attention on the actions implemented by Cloud Computing providers which, according to our results, are one of the most relevant predictors of eventual Cloud adoption. A deep knowledge of the suppliers acting in the market, their products and their capabilities (reputation, credibility, knowledge management, know-how, etc.) is needed (Koehler et al. 2010). Nowadays, companies may acquire experience and expertise by a technology provider as a partner in technologies developing (Doolin et al., 2003). Sustained observation of incumbent providers will help managers to choose and select the ones who are more capable of providing this technology in an efficient way. Likewise, managers would be able to build up an appropriate fit between the tools and resources provided by suppliers and their internal resources to create sustained competitive advantages. Technology providers with respect to their key role on adoption as well as the increasing complexity in the IT market, should be therefore chosen according to their willingness to cooperate and their ability to provide complementary capabilities to the firm. Furthermore, managers should create the adequate environment so that firms can carry out a sustained exercise of technological surveillance that, aside from classifying and evaluating technology providers, can identify Success Cases relevant to Cloud Computing adoption. Thus, firms could implement "technological benchmarking" to seize and apply the lessons learned outside the tasks that make up the business value chain. These implications are tightly related to the adoption scale we used (see Table 4). Success cases would be encouraging companies to venture in the world of Cloud Computing through experimental, departmental or inter-departmental clusters. This approach to technology providers would allow the development of Micro-clouds which in turn would nurture know-how among adopters. Technology providers and their capabilities would subsequently develop Private and Community Clouds. To develop a sound Community Cloud, the close cooperation among commercial partners will be key (Bruque et al., 2015), and 
technology providers will complement the capabilities of incumbent companies acting as real technological partners. Finally, companies hosting Public Clouds will strengthen the relationship between the technological provider and the business partner that will give rise to a greater success likelihood.

These results also have some public policy implications. Some directions for future adoption policies might entail infrastructure development, support to early adopters and creation of the necessary conditions so that $R \& D$ Institutions might be actually interested and connected in/to potential adopters. Public Administrations must foster cloud applications and Success Cases could be explained and shown through Pilot Centers in which Technology Providers, R\&D Institutions and Public Administrations might cooperate. Business associations related to IT also might deepen the diffusion activities of Cloud Computing among their partners and, particularly, he diffusion of Success Cases. In addition, public administrations should enable a stronger interconnection among the three agents, such as through new joint ventures that could be set up to lead the development of Cloud Computing applications. Furthermore, the creation of Spin-out companies from research results in universities and research centers can be another interesting future work direction for policy-makers, particularly if Technology suppliers are somehow involved in the initiative.

Drawing upon our analyses, it is possible to envision what is in the pipeline regarding business adoption of Cloud Computing. Overall, IT is moving towards an “industrialization process", by which IT is becoming a commodity. In the meantime, companies, influenced by IT providers will massively adopt Cloud Computing, leaving aside own IT infrastructures and services and moving onto pay-per-use models. These pay-per-use models will be provided by a bundle of highly specialized public cloud providers that will dominate the market. As an intermediate step, IT providers are currently boosting the use of hybrid clouds where public and private clouds coexist. Success cases, thanks to a positive feedback effect, will increase the influence of IT providers on adoption, which in turn will create new success cases.

\section{Conclusions, limitations and future research}

This work is the first research attempt aiming to identify the influence exerted over Cloud Computing adoption by R\&D Institutions, Technology Providers and Public Administrations, considering also other environmental variables such as Killer Applications and Success Cases. The results are relevant and have important 
implications to business practice: the only environmental agents with a significant role on adoption are Technology Providers. Neither R\&D Institutions nor Public Administrations have a recognizable effect on adoption. The existence and awareness of Success Cases have an important role on adoption while Killer Applications do not influence significantly.

This research has several limitations. First, data were only collected from HighTechnology firms located in Technology Parks in Spain. These relationships may not be the same for all industries or regions. Second, this research uses a cross-sectional design. Furthermore, the proposed theoretical model could be considered as a submodel of contingent theoretical frameworks which in turn entails offering a partial view of adoption.

Future research might study other industries less prone to risk themselves in high technology adoption initiatives or different countries and geographical settings so that they can make cross-national adoption comparisons, implications and recommendations. Finally, further research is needed about other internal drivers that may determine Cloud Adoption in companies, particularly in more advanced stages of adoption.

\section{References}

ABDULAZIZ A (2012) Cloud Computing for Increased Business Value. International Journal of Business and Social Science 3 (1), pp. 234-239.

ALSHAMAILA Y and PAPAGIANNIDIS S (2013) Cloud computing Adoption by SMEs in the North East of England: A Multi-perspective Framework. Journal of Enterprise Information Management 26, pp. 250-275.

ALSHAMAILA Y, PAPAGIANNIDIS S and STAMATI T (2013) Cloud Computing Adoption in Greece. In Proceedings of UK Academy for Information Systems Conference, pp. 1-17.

APTE, Asociación de Parques Científicos y Tecnológicos de España (2013) Directorio de Empresas e Instituciones, APTE, Málaga.

ARINZE B and ANANDARAJAN M (2010) Factors that Determine the Adoption of Cloud Computing: A Global Perspective. International Journal of Enterprise Information Systems 6 (4), pp. 55-68. 
BAGOZZI RP and YI Y (1988) On the evaluation of structural equation models. Journal of the Academy of Marketing Science 16 (1), pp. 74-94.

BAKOUROS YL, MARDAS DC and VARSAKELIS NC (2002) Science parks, a hightech fantasy? An analysis of the science parks in Greece. Technovation 22 (2), pp. 123-128.

BENLIAN A and HESS T (2011) Opportunities and risks of software-as-a-service: Findings from a survey of IT executives. Decision Support Systems, 52 (1), pp. 232-246.

BENTLER PM and WU EJC (2002) EQS for Windows user's guide. Multivariate Software Inc., Encino, California.

BRUQUE S, MOYANO J and MAQUEIRA, JM (2015) Cloud computing, Web 2.0, and operational performance: The mediating role of supply chain integration. The International Journal of Logistics Management 26 (3), pp. 426-458.

BUYYA R, BROBERG J and GOSCINSKI A (Eds) (2011) Cloud Computing: Principles and Paradigms. Wiley Press, New York.

BUYYA R, YEO CH, VENUGOPAL S, BROBERG J and BRANDIC I (2009) Cloud Computing and emerging IT platforms: Vision, hype, and reality for delivering computing as the $5^{\text {th }}$ utility. Future Generation Computer Systems 25 (6), pp. 599616.

CHAU PYK and TAM K (1997) Factors affecting the adoption of open systems: an exploratory study, MIS Quarterly 21 (1), pp. 1-24.

CEGIELSKI CG, JONES-FARMER LA, WU Y and HAZEN BT (2012) Adoption of Cloud Computing Technologies in Supply Chains: An Organizational Information Processing Theory Approach. International Journal of Logistic Management 23, pp. $184-211$.

CHATTERJEE D, GREWAL R and SAMBAMURTHY V (2002) Shaping up for ecommerce: institutional enablers of the organizational assimilation of Web technologies. MIS Quarterly 26 (2), pp. 65-89.

CHRIS R (2011) A break in the cloud? The reality of cloud computing. International Journal of Management and Information Systems 15 (4), pp. 59-63. 
DIMAGGIO PJ and POWELL WW (1983) The iron cage revisited: institutional isomorphism and collective and collective rationality in organizational fields. American Sociological Review 48 (2), pp. 147-160.

DIMITRAKOS T, MARTRAT J and WESNER S (2010) Service oriented infrastructures and cloud service platforms for the enterprise. A selection of common capabilities validated in real-life business trials by the BEinGRID Consortium. Springer, Berlin.

DOOLIN B, MCLEOD L, MCQUEEN B and WATTON M (2003) Internet Strategies for Established Retailers: Four New Zealand Case Studies, Journal of Information Technology Cases and Applications 5 (4), pp. 3-20.

DOS SANTOS BL and PEFFERS K (1998) Competitor and vendor influence on the adoption of innovative applications in electronic commerce. Information \& Management 34 (3), pp. 175-184.

FRAMBACH RT, BARKEMA HG, NOOTEBOOM B and WEDEL M (1998) Adoption of a service innovation in the business market: an empirical test of supply-side variables. Journal of Business Research 41 (2), pp. 161-174.

GUPTA P, SEETHARAMAN and RAJ J R (2013) The usage and adoption of cloud computing by small and medium business. International Journal of Information Management, 33, pp. 861-874.

HOVAV A, PATNAYAKUNI R and SCHUFF D (2004) A model of Internet standards adoption: the case of IPv6. Info Systems Journal 14 (4), pp. 265-294.

HSU P F, RAY and LI-HSIEH Y Y (2014) Examining cloud computing adoption intention, pricing mechanism, and deployment model, International Journal of Information Management, 31, pp. 474-488.

IYER B and HENDERSON J (2010) Preparing for the Future: Understanding the Seven Capabilities of Cloud Computing. MIS Quarterly Executive 9 (2), pp. 117-131.

JANSSEN M and JOHA A (2011) Challenges for adopting cloud-based software as a service (SaaS) in the public sector. ECIS-2011, Nineteenth European Conference on Information Systems, Helsinki (Finland), June 9-11. 
KENJI E, KUSHIDA KE, MURRAY J and ZYSMAN J (2011) Diffusing the Cloud: Cloud Computing and Implications for Public Policy. Journal of Industry Competition and Trade 11 (3), pp. 209-237.

KLINE RB (1998) Principles and practice of structural equation modelling. The Guilford Press, New York.

KOEHLER P, ANANDASIVAM A and Dan MA (2010) Cloud services from a consumer perspective. Proceedings of the Americas Conference on Information Systems.

KUAN KYK and CHAU PYK (2001) A perception-based model for EDI adoption in small businesses using a technology-organization-environment framework. Information \& Management 38 (8), pp. 507-521.

LEYDESDORFF L and ETZKOWITZ H (1996) Emergence of a Triple Helix of University- Industry-Government Relations. Science and Public Policy 23 (5), pp. 279-286.

LIAN JW, YEN DC and WANG YT (2014) An exploratory study to understand the critical factors affecting the decision to adopt cloud computing in Taiwan hospital, International Journal of Information Management 34, pp. 18-36.

LIAO S, SHAO YP, WANG H and CHEN A (1999) The adoption of virtual banking: an empirical study. Information \& Management 19 (1), pp. 63-74.

LIN A and CHEN NC (2012) Cloud Computing as an Innovation: Perception, Attitude, and Adoption. International Journal of Information Management 32, pp. 533-540.

LOW C, CHEN Y and WU M (2011) Understanding the determinants of cloud computing adoption. Industrial Management \& Data Systems 111 (7), pp. 10061023.

MAQUEIRA JM, BRUQUE S and MOYANO J (2009) What does Grid Information Technology really mean? Definitions, taxonomy and implications in the organisational field. Technology Analysis \& Strategic Management 21 (4), pp. 491513.

MAQUEIRA JM and BRUQUE S (2007) A review of trends and adoption model for Grid Information Technology. International Journal of Biotechnology 9 (6), pp. 607-634. 
MARSTON S, LI Z, BANDYOPADHYAY S, ZHANG J and GHALSASI A (2011) Cloud computing. The business perspective. Decision Support Systems 51 (1), pp. 176-189.

MELL P and GRANCE T (2011) The NIST Definition of Cloud Computing. National Institute of Standards and Technology.

MIDDLETON CA (2007) What if there is no killer application? An exploration of a user-centric perspective on broadband. Journal of Information Technology, 18 (4), pp. 231-246.

MONTEALEGRE R (1999) A temporal model of institutional interventions for information technology adoption in less-developed countries. Journal of Management Information Systems 16 (1), pp. 207-233.

MOORE GA (1991) Crossing the chasm. Marketing and selling high-tech products to mainstream customers. Harper Collins Publishers, New York.

MOORE GA (1995) Inside the tornado. Marketing Strategies from Silicon Valley’s cutting edge. Harper Collins Publishers, New York.

NAMBISAN S and WANG YM (1999) Roadblocks to Web technology adoption. Communications of the ACM 42 (1), pp. 98-101.

NAVONIL M (2010) Exploiting grid computing, desktop grids and cloud computing for e-science. Future directions. Transforming Government: People, Process and Policy 4 (4), pp. 288-298.

NUSEIBEH H (2011) Adoption of Cloud Computing in Organizations. In Proceedings of the $17^{\text {th }}$ Americas Conference on Information Systems, AMCIS 2011.

OLIVEIRA T, THOMAS M and ESPADA M (2014) Assessing the determinants of cloud computing adoption: An analysis of the manufacturing and services sectors, Information \& Management 51, (4), pp. 497-510.

PAN MJ and JANG WY (2008) Determinants of the adoption of enterprise resource planning within the technology-organization-environment framework: Taiwan's communications industry. The Journal of Computer Information Systems 48 (3), pp. 94-102. 
POWELL TC and DENT-MICALLEF A (1997) Information Technology as competitive advantage: the role of human, business, and technology resources. Strategic Management Journal 18 (5), pp. 375-405.

PREMKUMAR G (2003) A meta-analysis of research on information technology implementation in small business. Journal of Organizational Computing 13 (2), pp. 91-121.

PREMKUMAR G and ROBERTS M (1999) Adoption of new information technologies in rural small businesses. Omega International Journal of Management Science 27 (1), pp. 467-484.

PREMKUMAR G, RAMAMURTHY K and CRUM M (1997) Determinants of EDI adoption in the transportation industry. European Journal of Information Systems 6 (2), pp. 107-121.

QUADDUS M and HOFMEYER G (2007) An investigation into the factors influencing the adoption of B2B trading exchanges in small businesses. European Journal of Information Systems 16 (3), pp. 202-215.

REPSCHLAEGER, J, EREK K and ZARNEKOW R (2013) Cloud computing adoption: an empirical study of customer preferences among start-up companies. Electron Markets, 23, pp. 115-148.

ROGERS EM (1962) Diffusion of Innovations, Free Press, New York.

ROGERS EM (1995) Diffusion of Innovations, $4^{\text {th }}$ ed., Free Press, New York.

ROGERS EM and SHOEMAKER FF (1971) Communications of innovations: a cross cultural approach, $2^{\text {nd }}$ ed. Free Press, New York.

SALWANI MI, MARTHANDAN G, NORZAIDI M and CHONG SC (2009) Ecommerce usage and business performance in the Malaysian tourism sector: empirical analysis. Information Management \& Computer Security 17 (2), pp. 166185.

SATORRA A (2002) Asymptotic robutness in multiple group linear-latent variable models. Econometric Theory 18 (2), pp. 297-312.

SHIN DH (2006) Prospectus of mobile TV: Another bubble or killer application? Telematics and Informatics, 23 (4), pp. 253-270. 
SOLIMAN KS and JANZ BD (2004) An exploratory study to identify the critical factors affecting the decision to establish Internet-based interorganizational information systems. Information \& Management, 41 (6), pp. 697-706.

SON I, LEE D, LEE, J-N, CHANG, Y B (2014) Market perception on cloud computing intitiatives in organizations: A extended resource-based view. Information \& Management 51 (6), pp. 653-669.

SYNODINOS NE and BRENNAN JM (1988) Computer Interactive Interviewing in Survey Research. Psychology \& Marketing 5 (2), pp. 117-137.

TEO TSH, TAN M and BUK WK (1997) A contingency model of internet adoption in Singapore. International Journal of Electronic Commerce 2 (2), pp. 95-118.

TEO TSH and PIAN Y (2003) A contingency perspective on Internet adoption and competitive advantage. European Journal of Information Systems 12 (2), pp. 7892.

TEO TSH and PIAN Y (2004) A model for Web adoption. Information \& Management 41 (4), pp. 457-468.

THONG JYL (1999) An integrated model of Information Systems adoption in small businesses. Journal of Management Information Systems 15 (4), pp. 187-214.

TORNATZKY LG and FLEISCHER M (1990) The Processes of Technological Innovation. Lexington Books, Lexington.

TUNCAY E (2010) Effective use of cloud computing in education institutions. Procedia Social and Behavioral Sciences 2 (2), pp. 938-942.

VELTEN C and JANATA S (2011) Cloud Vendor Benchmark 2011. A Comparison of Cloud Computing Vendors. Experton Group AG, Ismaning.

WANG CC, HSU Y and FANG W (2005) Acceptance of technology with network externalities: an empirical study. Journal of Information Technology Theory and Application 6 (4), pp. 15-28.

WINANS TB and BROWN JS (2009) Moving Information Technology platforms to the Clouds: Insights into IT platform architecture transformation. Journal of Service Science 2 (2), pp. 23-33. 
WU L (2006) Resources, dynamic capabilities and performance in a dynamic environment: Perceptions in Taiwanese IT enterprises. Information \& Management 43 (4), pp. 447-454.

XU G and GUTIÉRREZ JA (2006) An exploratory study of killer applications and critical success factors in m-commerce. Journal of Electronic Commerce in Organizations 4 (3), pp. 63-79.

YANG SO and HSU C (2011) The organizing vision for Cloud Computing in Taiwan. Journal of Electronic Commerce Research 12 (4), pp. 257-271.

ZHANG Y and SI C (2008) The impacts of external factors on the growth of Chinese entrepreneurial enterprises. An empirical study. Journal of Small Business and Enterprise Development 15 (4), pp. 689-703. 